Mário Antônio Sanches ${ }^{1}$ Daiane Priscila Simão-Silva ${ }^{1}$ Houda Izabela de Oliveira ${ }^{1}$

\title{
RELAÇÃO ENTRE A DIGNIDADE DA PESSOA COM DEFICIÊNCIA E O VALOR DE EMBRIÕES HUMANOS
}

The relation between the dignity of the disabled person and the value of human embryos

${ }^{1}$ Pontifícia Universidade Católica do Paraná. Curitiba/PR, Brasil. Correspondência: Mário Antônio Sanches. E-mail: m.sanches@pucpr.br

Recebido: 18/05/2018. Revisado: 22/11/2018. Segunda revisão: 19/12/2018. Aprovado: 21/12/2018. 


\section{RESUMO}

Nas últimas décadas, foi notória a ampliação da oferta de testes genéticos de diagnóstico pré-natal, inclusive para fins de interrupção de gravidez ou descarte de embriões na reprodução assistida. Paralelamente, surgiram muitos movimentos e organizações no sentido de afirmar a dignidade das pessoas com deficiência e seu direito a uma vida plenamente incluída na sociedade. Este artigo pretende analisar esses dois movimentos e destacar suas contradições. Questionamos se é possível dissociar as práticas de eliminação de embriões e fetos anômalos dos pressupostos eugênicos do início do século XX, bem como a coerência dessas práticas. A reflexão é conduzida considerando que, claramente, estamos assistindo a movimentos que apontam para posições opostas e que a discussão precisa ser ampliada de forma coerente. Os movimentos em prol das pessoas com deficiência já alcançaram muitos avanços legislativos e políticos nas últimas décadas, contudo ainda têm muito a enfrentar em relação ao modelo médico ou determinista de deficiência, construído e reforçado socialmente apontando a deficiência como um problema a ser eliminado. $\mathrm{O}$ ápice desse discurso se dá na legitimidade conferida aos testes genéticos como forma de superação do problema das deficiências através da eliminação do próprio "deficiente".

\section{Palavras-Chave:}

Bioética; Eugenia; Testes genéticos; Violência simbólica.

\section{ABSTRACT}

In the last few decades, it has been notorious the increased offer of genetic testing for prenatal diagnosis as well as their application for pregnancy interruption or discarding embryos in assisted reproduction. At the same time, many movements and organizations have emerged to affirm the dignity of people with disabilities and their right to the full inclusion of their lives in society. This article intends to analyze these two movements and highlight their contradictions. We question whether it is possible to dissociate the anomalous embryo and fetus disposal practices from eugenics' assumptions of the early twentieth century, and the consistency of such practices. The deliberation is conducted considering that clearly we are looking at movements that point to opposite directions and the discussion needs to be expanded coherently. Movements in favor of people with disabilities have already achieved many legislative and political advances in recent decades, however, they still have a lot to confront in relation to the medical or deterministic model of disability, which has been built and socially reinforced pointing disability as a problem to be eliminated. This discourse peaks with the legitimacy conferred to genetic testing as a way of overcoming the problem of disabilities by eliminating the "disabled" themselves.

\section{Keywords:}

Bioethics; Eugenics; Genetic Testing; Symbolic Violence. 


\section{Introdução}

Nas últimas décadas, têm sido ampliadas as possibilidades de teste genético em embriões e fetos humanos, cujos resultados permitem às pessoas envolvidas tomar decisões que, com muita frequência, têm sido de não viabilizar a vida dos fetos e embriões identificados como anômalos - e, portanto, não realizar a transferência de embriões para o útero materno ou induzir a uma interrupção de gravidez.

Paralelamente a essas novas possibilidades e práticas, nossa sociedade tem assistido ao surgimento de associações de pessoas com deficiência, familiares e amigos com o objetivo de afirmar a dignidade delas e seu amplo direito a uma vida plenamente incluída na sociedade. Como fruto desses movimentos, têm surgido no Brasil leis e políticas que visam a assegurar o direito das pessoas com deficiência ao exercício pleno de cidadania e à inclusão social. Um dos objetivos dessa normatização é a superação de todo tipo de violência contra pessoas com deficiência, com destaque para o fim da violência ocorrida na infância.

Este artigo pretende analisar esses dois movimentos e indagar sobre suas contradições. É possível justificar a eliminação de um feto com a possibilidade, detectada em um teste genético, de ele nascer com determinada síndrome, sendo que a sociedade tem aprovado leis para defender as pessoas com essa mesma síndrome? É possível dissociar tais práticas - eliminação de embriões e fetos anômalos - dos pressupostos eugênicos do início do século XX? É possível defender uma eugenia familiar? Ou seja, é coerente a prática de deixar aos pais a decisão a respeito da eliminação de fetos com anomalias?

Como se sabe, este artigo não aborda uma possibilidade, mas uma prática, pois muitos países e muitas pessoas já assumiram claramente a eliminação de embriões e fetos diagnosticados com determinadas características genéticas. Estamos cientes de que os pais que tomaram tais decisões o fizeram a partir de sua própria realidade existencial e pessoal, não cabendo à bioética julgá-los. No entanto, a indagação permanece: claramente, há movimentos que apontam para posições que podem ser consideradas opostas, e a reflexão precisa ser ampliada, pois a ética exige argumentos coerentes.

Destaca-se que a reprodução assistida (RA), contexto em que usualmente se realiza seleção embrionária, suscita amplo debate. Nesse debate, não há consenso ético nem mesmo jurídico, pois "a formulação das legislações [sobre o tema] está profundamente enraizada na cultura de uma nação. Por esse motivo, provavelmente nunca existirá um consenso mundial sobre a licitude ética dos procedimentos realizados"1.

Os testes em questão foram viabilizados pelo desenvolvimento da genética no século XX. Assim, será feita a seguir uma breve análise da relação entre genética e eugenia. Na sequência, apresentamos as possibilidades proporcionadas pelos testes genéticos, o movimento de inclusão de pessoas com deficiência na sociedade 
brasileira e a busca de superação da violência contra essas pessoas, com considerações sobre o tema controverso.

\section{A superação da mentalidade eugenista na história da genética}

$\mathrm{O}$ fato de a ciência genética ter surgido e se desenvolvido num contexto de mentalidade eugênica é conhecido, mas há também consenso de que, após a segunda metade do século XX, buscou distanciar-se da eugenia - demonstrando, de várias maneiras, que esse distanciamento é possível ${ }^{2}$. Vamos mapear brevemente esse duplo contexto da genética.

Condit ${ }^{3}$ apresenta que a história da genética está relacionada com a história da eugenia, sendo esta última compreendida como a primeira fase do desenvolvimento da nova ciência. O termo "eugenia", oriundo do grego eugenes ou "bem nascido”, é proposto no final do século XIX por Galton, que o entendia como o estudo que promoveria o melhoramento racial das futuras gerações ${ }^{4}$. Em 1907, surgiu a Sociedade Britânica para a Educação Eugênica ${ }^{5}$.

O movimento eugênico surgiu também nos Estados Unidos com um objetivo claramente definido, propondo programas de controle para aumentar o número

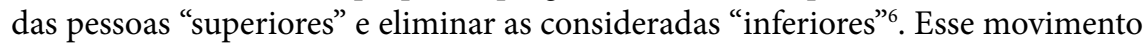
baseou-se nas obras de Davenport - Heredity in Relation to Eugenics, de $1911^{7}$ - e de Grant - no livro The Passing of the Grate Race. Em 1923, foi fundada a Sociedade Eugênica Americana com filiais em 28 estados americanos ${ }^{8}$. As consequências da eugenia nos Estados Unidos foram muitas, mas as mais visíveis foram a esterilização de milhares de pessoas e as restrições à imigração.

Espalhando-se por diversos países, foi na Alemanha que a eugenia alcançou maior notoriedade e dramaticidade. Destacamos que Adolf Hitler apropriou-se das ideias eugenistas, mas não as elaborou; assim, o movimento eugênico validou o nazismo, como faria com qualquer outro movimento racista. Muitas instituições eugenistas alemãs tiveram seu início no começo do século passado, antes do nazismo - por exemplo, em 1920, muitos professores alemães participaram do movimento eugênico internacional e, em 1927, foi fundado o Instituto de

\footnotetext{
${ }^{2}$ SANCHES, Mário Antônio. Brincando de Deus: bioética e as marcas sociais da genética. São Paulo: Ave Maria, 2007. p. 78.

${ }^{3}$ CONDIT, Celeste Michele. The meanings of the gene: public debates about human heredity. Madison: University of Wisconsin Press; 1999. p.5.

${ }^{4}$ DYCK, Arthur J. Eugenics in historical and ethical perspective. In: KILNER, John F.; PENTZ, Rebecca D.; YOUNG, Frank (Eds.). Genetic ethics: do the ends justify the genes? Grand Rapids: Eerdmans Publishing Company, 1997. p. 25-39.

${ }^{5}$ BUCHANAN, Allen, BROCK, Dan W., DANIELS, Norman. From chance to choice: genetics and justice. New York: University Press Cambridge, 2000. p. 31.

${ }^{6}$ CONDIT, Celeste Michele. op. cit., p. 43.

${ }^{7}$ MARKS, Jonathan. Human biodiversity: genes, race and history. New York: Aldine de Gruyter, 1995. p. 81.

${ }^{8}$ BUCHANAN, Allen, BROCK, Dan W., DANIELS, Norman. op. cit., p. 31.
} 
Antropologia, Hereditariedade Humana e Eugenia “Kaiser Wilhelm”. Não cabe aqui uma exposição completa das práticas nazistas realizadas e justificadas na época a partir dos pressupostos da eugenia, mas é bom lembrar a lei de esterilização eugênica, em $1933^{9}$, e a eutanásia para certas classes de doentes mentais ou deficientes nos asilos alemães a partir de 1939.

Após os fatos da Segunda Guerra Mundial virem à tona, notou-se a preocupação mais forte dos geneticistas em se distanciar da eugenia, surgindo o que se chamou de "nova genética". Ao se dissociar do movimento eugênico a genética tornou-se a área da biologia que mais se desenvolveu na segunda metade do século XX. Inúmeras pesquisas genéticas têm demonstrado a unidade genômica entre todos os pertencentes à espécie Homo sapiens, paralelamente à valorização da diversidade genética existente entre os indivíduos humanos. Reconhecimento dessa unidade e valorização da diversidade são dois argumentos contrários às teses eugênicas.

Além do avanço da genética, os pressupostos do movimento eugênico do século passado foram questionados também pelo desenvolvimento das ciências sociais e pela crescente consciência ética e de direitos humanos, que promove o respeito e a valorização da diversidade humana, tanto biológica quanto cultural. Mas, pelo fato de a genética ser a ciência da hereditariedade e prometer grandes benefícios à humanidade, "é inevitável que a genética de hoje ocorra nas sombras da eugenia"10.

Desse modo, a eugenia continua sendo apresentada por vários autores como o grande problema ético colocado pelas pesquisas em biotecnologia ${ }^{11}$ e, em vários momentos, percebe-se que ela deixa de ser coisa do passado e se mostra ainda ser uma realidade atual ${ }^{12}$.

Em sua origem histórica, a eugenia era apresentada como ciência que promovia o melhoramento das qualidades inatas da raça, desenvolvendo-as ao máximo ${ }^{13}$. Era voltada à melhoria de qualidade das futuras gerações ${ }^{14}$, acreditando que os traços favoráveis são sempre inatos ${ }^{15}$. Deste modo, a eugenia tem diferentes significados e hoje suas fronteiras continuam bastante indefinidas ${ }^{16}$, incluindo aspectos subjetivos das pessoas envolvidas ${ }^{17}$.

\footnotetext{
${ }^{9}$ KELVES, Daniel J. In the name of eugenics: genetics and the uses of human heredity. New York: Alfred A. Knopf, 1985. p. 116.

${ }^{10}$ BUCHANAN, Allen, BROCK, Dan W., DANIELS, Norman. op. cit., p. 28.

${ }^{11}$ SLOAN, Philip R. Controlling our destinies: historical, ethical, and theological perspectives on the Human Genome Project. Notre Dame: University of Notre Dame Press, 2000. p. 185.

${ }^{12}$ DYCK, Arthur J. op. cit., p. 37.

${ }^{13}$ CONDIT, Celeste Michele. op. cit., p. 5.

${ }^{14}$ DYCK, Arthur J. op. cit., p. 26.

${ }^{15}$ MARKS, Jonathan. op. cit., p. 78.

${ }^{16}$ CONDIT, Celeste Michele. op. cit., p. 28.

${ }^{17}$ BERNAL, Ricardo Miguel Luque; BEJARANO, Roberto José Buitrago. Is genetic counseling a form of eugenics? Rev. Cienc. Salud, Bogotá-CO, v.16, n. 1, p. 10-26, ene./abr. 2018.
} 
Para não confundir práticas de medicina preditiva e preventiva com a eugenia, defendemos aqui que esta deve continuar sendo entendida no sentido clássico, ou seja: a eugenia - em sua forma positiva - é todo esforço de passar às gerações futuras determinados traços genéticos, hereditários ou não, na pressuposição de que tais traços sejam superiores e de que todos os indivíduos portadores desses traços se tornariam, portanto, superiores ou melhores do que os outros, tanto biológica como socialmente; e - em sua forma negativa - é todo esforço de eliminar ou esterilizar os seres humanos que sejam portadores de traços genéticos tidos como indesejáveis ou inferiores biológica e socialmente.

Alguns cientistas, conhecidos como "eugenistas utópicos", defendem uma eugenia sem preconceito de raça ou de classe $^{18}$ e pressupõem que cada casal teria direito a sua própria e livre decisão, que esta decisão seria bem informada e consciente e que a informação genética seria correta ${ }^{19}$. Novamente, nos deparamos com uma confusão: não estaríamos, assim, diante de uma ideologia mascarada de pretensão humanitária? A defesa da liberdade do casal para escolher pela eugenia, a nosso ver, não torna a eugenia mais aceitável nem eticamente correta.

No esforço de delimitar a eugenia, recorremos a Buchanan et al. ${ }^{20}$, que apontam cinco teses que explicam por que a eugenia histórica estava errada: (i) substituição ao invés de terapia; (ii) não valorização da diversidade (o ideal humano tornava-se a semelhança com o dos eugenistas); (iii) violação dos direitos reprodutivos; (iv) estatismo; e (v) injustiça. Ou seja, a eugenia propriamente dita não promove terapia, mas eliminação de pessoas doentes; não valoriza a diversidade humana, mas qualifica alguns como superiores; desrespeita o direito de todos de se reproduzirem; é arrogante (não necessariamente estatal); e é injusta.

Por fim, podemos concluir que a dificuldade de conceituar eugenia dá-se pelo fato de ela ter sido introduzida originalmente como ciência e, como tal, teria objeto específico e métodos próprios.

Compreendemos, todavia, que a eugenia não é uma ciência, mas antes uma ideologia, que lança mão de algumas ciências, especialmente da genética, para cumprir seus objetivos, fundamentados nos pressupostos que a mantém.

\section{A prática dos testes genéticos e o que ela possibilita}

O desenvolvimento da genética promoveu, no final da década de 1970, uma verdadeira "caça" aos genes responsáveis por doenças humanas. Conforme relatam

\footnotetext{
${ }^{18}$ KELVES, Daniel J. op. cit., p. 11.

${ }^{19}$ KITCHER, Philip. Utopian eugenics and social inequality. In: SLOAN, Phillip R. (Ed.). Controlling our destinies: historical, ethical, and theological perspectives on the Human Genome Project. Notre Dame: University of Notre Dame Press, 2000. p. 237.

${ }^{20}$ BUCHANAN, Allen, BROCK, Dan W., DANIELS, Norman. op. cit., p.46-52.
} 
Watson e Berry ${ }^{21}$, foi uma história protagonizada principalmente por organizações criadas por pessoas com uma vivência pessoal das mazelas provocadas pelas deficiências genéticas.

Todos esses esforços, somados ao sequenciamento completo do genoma humano, resultaram em um avanço significativo, nos últimos 30 anos, no diagnóstico das deficiências de origem genética. Contudo, esse conhecimento traz um novo desafio: o que fazer com essas informações?

Na década de 1950, já era possível contar com a citogenética como instrumento de diagnóstico para anomalias no número de cromossomos. Em 1986, o teste foi utilizado pela primeira vez como exame pré-natal fetal para diagnóstico de síndrome de Down. Posteriormente, a análise do cariótipo tornou-se o "padrão ouro" para o diagnóstico pré-natal de alterações cromossômicas. Contudo, a obtenção do material genético fetal pelo método tradicional consiste em um procedimento invasivo, com risco de perda da gestação entre $1,0 \%$ e 2,0\% ${ }^{22}$. No fim dos anos 1990, com a identificação da presença de DNA fetal no sangue materno ${ }^{23}$, surgiu a possibilidade do desenvolvimento de novas ferramentas diagnósticas não invasivas para as doenças cromossômicas.

O primeiro teste pré-natal não invasivo (NIPT) foi utilizado clinicamente em 2011 para triagem de alterações cromossômicas e hoje é uma técnica amplamente difundida no mercado de testes diagnósticos pré-natal. O método não está restrito ao diagnóstico de doenças cromossômicas, permitindo também a detecção de outras alterações genéticas, como doenças monogênicas - apesar de não realizado por questões éticas e de custo, é possível até mesmo o diagnóstico de variantes de predisposição para doenças poligênicas, através da análise do genoma completo.

Os testes genéticos pré-natais de diagnóstico permitem a identificação do sexo do feto, da paternidade e o diagnóstico genético clínico. Na maioria dos casos em que o diagnóstico clínico revela que o feto é portador de alguma deficiência de origem genética, não é possível nenhum tipo de intervenção que venha a beneficiar a saúde da criança que virá a nascer. Uma das possibilidades profiláticas pré-natal é a prevenção da aloimunização materna a partir da identificação genética de $\mathrm{RhD}$ fetal, quando a mãe é fator $\mathrm{RhD}$ negativo e feto pode ser positivo. ${ }^{24}$ As cirurgias

\footnotetext{
${ }^{21}$ WATSON, J. D; BERRY, A. DNA: o segredo da vida. Trad. Carlos Afonso Malferrari. São Paulo: Companhia das Letras, 2005. p. 346.

${ }^{22}$ TABOR, A; ALFIREVIC, Z. Update on procedure-related risks for prenatal diagnosis techniques. Fetal Diagn Ther, v. 27, n. 1, p. 1-7, Dec. 2009. http://dx.doi.org/10.1159/000271995.

${ }^{23} \mathrm{LO}$, Y. M. et al. Presence of fetal DNA in maternal plasma and serum. Lancet, v. 16, n. 350, p. 485-487, Aug. 1997. http://dx.doi.org/10.1016/S0140-6736(97)02174-0.

${ }^{24}$ SCHMIDT, L. C. et al. Noninvasive fetal RHD genotyping from maternal plasma in an admixed Brazilian population. Genet Mol Res, Ov. 13, n. 1, p. 799-805, Feb. 2014.
} 
fetoscópicas também são uma possibilidade de tratamento para doenças genéticas como a onfalocele ${ }^{25}$.

Outra modalidade de teste genético reprodutivo são os testes pré-implantatórios (PGD e PGS), que permitem escolher pela não transferência para o útero de embriões portadores de alguma deficiência.

O PGD é uma metodologia diagnóstica utilizada desde os anos $1990^{26}$ para a análise dos embriões formados a partir de reprodução assistida (RA) por fertilização in vitro (FIV) ou por injeção intracitoplasmática de espermatozoides (ICSI) no óvulo. Em ambas as técnicas, é possível a retirada de um ou dois blastômeros dos embriões obtidos para análise do material genético, com riscos de impacto sobre a viabilidade do embrião ${ }^{27}$.

Enquanto o PGD propicia a identificação de alterações genéticas específicas, o PGS possibilita um screening genético, com avaliação de todos os cromossomos. É possível, ainda, a avaliação por sequenciamento do exoma completo (whole-exome sequencing - WES) ou do genoma completo (whole-genome sequencing-WGS), no qual atualmente é possível a identificação molecular de 6.289 doenças genéticas ${ }^{28}$. O PGD é recomendado para casais com alto risco de alterações cromossômicas estruturais ou doenças monogênicas, enquanto o PGS é indicado para gestação precedida por abortos espontâneos repetidos, fracassos repetidos nas implantações embrionárias ou infertilidade com probabilidade de superação por FIV/ICSI ${ }^{29}$. Não há diretrizes ou recomendações para o uso de WES ou WGS ${ }^{30}$.

No Brasil, as técnicas de RA só podem ser aplicadas no intuito de selecionar o sexo ou outras características biológicas do embrião quando se tratar de evitar alguma doença que o filho venha a apresentar. Já os embriões com diagnóstico de alterações genéticas causadoras de doenças podem ser doados para pesquisa ou descartados ${ }^{31}$.

\footnotetext{
${ }^{25}$ GRAVES, C.E.; HARRISON, M.R.; PADILLA B.E. Minimally invasive fetal surgery. Clin Perinatol, v. 44, n. 4, p. 729-751, 2017. http://dx.doi.org/10.1016/j.clp.2017.08.001.

${ }^{26}$ HANDYSIDE, A.H et al. Pregnancies from biopsied human preimplantation embryos sexed by Y-specific DNA amplification. Nature, v. 19, n. 344, p. 768-770, Apr. 1990. http://dx.doi.org/10.1038/344768a0.

${ }^{27}$ KULIEV, A; VERLINSKY, Y. Preimplantation diagnosis: a realistic option for assisted reproduction and genetic practice. Current Opinion in Obstetrics and Gynecology, v. 17, n. 2, p. 179-183, May 2005. http://dx.doi. org/10.1097/01.gco.0000162189.76349.c5.

${ }^{28}$ OMIM Gene Map Statistics. Disponível em: http://www.omim.org/statistics/geneMap. Acesso em: 07 nov. 2018.

${ }^{29}$ ROTTERDAM ESHRE/ASRM-Sponsored PCOS Consensus Workshop Group. Revised 2003 consensus on diagnostic criteria and long-term health risks related to polycystic ovary syndrome. Fertil Steril, v. 81, n. 1, p.19-25, Jan. 2004. http://dx.doi.org/10.1016/j.fertnstert.2003.10.004.

${ }^{30}$ BORGHESI, Alessandro et al. Intersociety policy statement on the use of whole-exome sequencing in the critically ill newborn infant. Italian Journal of Pediatrics, v. 43, n. 100, 2017. Disponível em: https:// ijponline.biomedcentral.com/articles/10.1186/s13052-017-0418-0.

${ }^{31}$ CONSELHO FEDERAL DE MEDICINA. Resolução n. 2.168/2017. Adota as normas éticas para a utilização
} 
Evidentemente, o avanço do conhecimento científico trouxe novas possibilidades no campo da reprodução humana e as técnicas de RA têm um importante papel na resolução de problemas reprodutivos. E, nesse contexto da biotecnologia reprodutiva, a ciência genética contribui de forma significativa:

Previsivelmente, assim como a anticoncepção modificou pautas reprodutivas em certas populações, a genética, à medida que se incorpora na vida cotidiana, irá gerar outras mudanças reprodutivas. A decisão de procriar provavelmente assumirá, então, novas responsabilidades e obrigações. ${ }^{32}$

Os testes genéticos na RA justificam-se pelas estimativas de que mais de $50 \%$ dos embriões gerados com essa técnica são portadores de anomalias cromossômicas, independentemente da idade materna ${ }^{33}$. Nesse sentido, é possível indagar: por que um casal com oportunidade de escolha não evitaria o nascimento de um filho com deficiência?

Diante das aproximações argumentativas feitas entre a escolha da criança saudável e perfeita com o sistema eugênico vivido no século passado, surge a resposta de que o aconselhamento genético, em oposição aos princípios eugênicos estatais, vem em defesa dos interesses individuais da família, e não de interesses sociais ${ }^{34}$. Contudo, cabe a reflexão sobre quais são os interesses sociais em relação às crianças portadoras de deficiência e, na estrutura social, quais são os normalizadores ou esquemas da integração da pessoa com deficiência na família e na sociedade. Por exemplo: é possível eliminar um feto com Down sem passar uma mensagem para a sociedade de que pessoas com essa síndrome não são bem-vindas?

Pode parecer confusa a fronteira entre a eugenia e a preocupação com a saúde nas técnicas de medicina embrionária e fetal, mas nos parece que a fronteira pode se definir entre duas posturas básicas: uma é realizar testes em embriões e fetos com o objetivo de prever doenças e promover seu tratamento, e a outra é realizar testes em embriões e fetos para que, se estiverem doentes, eles sejam eliminados. Ao se realizar o PGD, há sempre que se considerar os riscos ao embrião ${ }^{35}$.

das técnicas de reprodução assistida - sempre em defesa do aperfeiçoamento das práticas e da observância aos princípios éticos e bioéticos que ajudam a trazer maior segurança e eficácia a tratamentos e procedimentos médicos - , tornando-se o dispositivo deontológico a ser seguido pelos médicos brasileiros e revogando a Resolução CFM n. 2.121, publicada no DOU. de 24 de setembro de 2015, Seção I, p. 117. Disponível em: https://sistemas.cfm.org.br/normas/visualizar/resolucoes/BR/2017/2168. Acesso em: 01 mar. 2020.

${ }^{32}$ LUNA, Florencia; RIVERA LÓPEZ, Eduardo. Ética y genética: los problemas morales de la genética humana. Buenos Aires: Catálogos, 2004. p. 15.

${ }^{33}$ WOLFF, P; MARTINHAGO, C.D; UENO, J. Diagnóstico genético pré-implantacional: uma ferramenta importante para a rotina de fertilização in vitro? Femina, v. 37, n. 6, p. 297-303, jun. 2009.

${ }^{34}$ BEIGUELMAN, Bernard. Genética e ética. In: PESSINI, Leo, BARCHIFONTAINE, Christian de Paul (Orgs.). Fundamentos da bioética. São Paulo: Paulus; 1996. p.108-123.

${ }^{35}$ MARAMBIO, José Tomás Alvarado; ALCÁNTARA, Manuel J. Santos. Ethical problems with the preimplantation genetic diagnosis of human embryos. Acta Bioethica, v. 24, n. 1, p. 75-83, 2018. Disponível em: https:// 


\section{O movimento de inclusão e defesa da pessoa com deficiência}

Desde o final da década de 1970, o Brasil vem avançando na criação de políticas, leis, programas e serviços visando à inclusão social. A inclusão não é apenas a garantia dos direitos da pessoa, mas também o combate da exclusão aos benefícios da vida em sociedade. No contexto internacional, o movimento de inclusão foi impulsionado pela Declaração Universal dos Direitos Humanos, de 1948. A partir desse documento, as pessoas com deficiência passaram a reivindicar direitos não apenas no campo da assistência social, mas também dos direitos humanos.

Embora já houvesse movimentos pelo reconhecimento da dignidade e em defesa das pessoas com deficiência, os movimentos protagonizados pelas próprias pessoas com deficiência em busca de autonomia - com o lema "Nada sobre Nós sem Nós” - só passaram a ocorrer a partir do fim dos anos 1970. Durante o século XX no Brasil, as ações do Estado em prol das pessoas com deficiência foram mínimas, havendo algumas iniciativas da sociedade civil - como a Sociedade Pestalozzi, criada em 1945, e a Associação de Pais e Amigos dos Excepcionais (Apae), fundada em 1954, que visavam à assistência para pessoas com deficiência intelectual ${ }^{36}$.

Os movimentos associativos de pessoas com deficiência ganharam forças e, quando a Organização das Nações Unidas (ONU) promulgou o Ano Internacional das Pessoas Deficientes (AIPD), que seria em 1981, foi criada uma Coalizão Pró-Federação Nacional. Entre 1980 e 1983, a Coalizão realizou encontros nacionais visando a compor uma única Federação Nacional de Entidades de Pessoas Deficientes, assim como à proposição de uma agenda de reivindicações e estratégias de reconhecimento de seus direitos humanos. A partir das discussões, identificou-se a necessidade da criação de federações nacionais por tipo de deficiência, e não uma federação única, devido à diversidade de cada movimento ${ }^{37}$.

O AIPD trouxe para as pessoas com deficiência no Brasil a possibilidade de se tornarem juntamente com suas reivindicações pelo direito de integrar e participar da vida em sociedade, como estabelecido na Carta para a década de Oitenta da $\mathrm{ONU}^{38}$, incluindo acesso à educação e ao mercado de trabalho. Naquela década,

scielo.conicyt.cl/pdf/abioeth/v24n1/1726-569X-abioeth-24-01-00075.pdf.

${ }^{36}$ POLÍTICA Nacional de Educação Especial na Perspectiva da Educação Inclusiva. Brasília-DF: MEC/SEESP, 2008. Documento elaborado pelo Grupo de Trabalho nomeado pela Portaria n. 555/2007, prorrogada pela Portaria n. 948/2007, entregue ao Ministro da Educação em 07 de janeiro de 2008. Disponível em: http:// portal.mec.gov.br/arquivos/pdf/politicaeducespecial.pdf.

${ }^{37}$ LANNA JÚNIOR, Mário Cléber Martins (Org.). História do movimento político das pessoas com deficiência no Brasil. Brasília-DF: Secretaria de Direitos Humanos, Secretaria Nacional de Promoção dos Direitos da Pessoa com Deficiência, 2010. Disponível em: http://www.mpsp.mp.br/portal/page/portal/ documentacao_e_divulgacao/doc_biblioteca/bibli_servicos_produtos/BibliotecaDigital/BibDigitalLivros/ TodosOsLivros/historia_movimento_pcd_brasil.pdf.

${ }^{38}$ BATTISTELLA, Linamara Rizzo. Celebrando os 30 anos do AIPD: uma história de lutas e conquistas de 
o que o movimento almejava era a igualdade de direitos, reivindicando que fossem garantidos constitucionalmente. Até então, havia uma única Emenda Constitucional, de $1978^{39}$, que, em artigo único, definia o que era assegurado aos deficientes: "a melhoria de sua condição social e econômica”.

Em 1986, os movimentos de pessoas com deficiência tiveram espaço na Assembleia Nacional Constituinte (ANC) que elaborava a Constituição da República Federativa do Brasil, participando do ciclo de encontros "A Constituinte e os portadores de deficiência" ${ }^{40}$. No período, não havia nenhum órgão gestor de políticas para pessoas com deficiência, sendo responsabilidade do Ministério da Educação e da Cultura a elaboração de políticas voltadas para essa população. Num segundo momento, na etapa de discussões sobre o anteprojeto da Constituição, os movimentos elaboraram um documento para a ANC que destacava a preocupação com a proposta de um capítulo específico sobre pessoas com deficiência. Para eles, essa proposta trazia uma lógica segregacionista, em que o tema da deficiência não estaria distribuído em todos os artigos constitucionais. Posteriormente, vendo que as reivindicações não haviam sido incorporadas de forma adequada, providenciaram um projeto de Emenda Popular contendo 14 artigos que sugeriam alterações no projeto da Constituição e reclamavam a igualdade de direitos.

Uma ação governamental em resposta ao envolvimento público em defesa dos direitos das pessoas com deficiência foi a criação, em 1986, da Política e da Coordenadoria Nacional para Integração da Pessoa Portadora de Deficiência (CORDE), com a promulgação da Lei n. 7.853/1989 ${ }^{41}$. Em 1999, com o Decreto n. 3.298/1999 a lei foi finalmente regulamentada, alterando a Política Nacional para Integração da Pessoa Portadora de Deficiência. No mesmo ano, foi criado o Conselho Nacional dos Direitos da Pessoa Portadora de Deficiência (Conade), pelo Decreto n. 3.076/199943. Após várias alterações, em 2003 a política para a pessoa com deficiência passou a ter vínculo direto com a Presidência da República, passando o Conade de estrutura

direitos. In: 30 ANOS do AIPD: Ano Internacional das Pessoas Deficientes 1981-2011. São Paulo: Imprensa Oficial do Estado de São Paulo, 2011. Disponível em: http://uniapae.apaebrasil.org.br/wp-content/ uploads/2019/10/30-ANOS-DO-AIPD-ANO-INTERNACIONAL-DAS-PESSOAS-DEFICIENTES-1981-2011.pdf.

${ }^{39}$ POLÍTICA Nacional de Educação Especial na Perspectiva da Educação Inclusiva. Brasília-DF: MEC/SEESP, 2008, cit.

${ }^{40}$ LANNA JÚNIOR, Mário Cléber Martins (Org.). op. cit., p. 63.

${ }^{41}$ BRASIL. Lein. 7.853, de 24 de outubro de 1989. Dispõe sobre o apoio às pessoas portadoras de deficiência, sua integração social, sobre a Coordenadoria Nacional para Integração da Pessoa Portadora de Deficiência - Corde institui a tutela jurisdicional de interesses coletivos ou difusos dessas pessoas, disciplina a atuação do Ministério Público, define crimes, e dá outras providências. Disponível em: http://www.planalto.gov.br/ ccivil_03/LEIS/L7853.htm. Acesso em: 11 dez. 2019.

${ }^{42}$ BRASIL. Decreto n. 3.298, de 20 de dezembro de 1999. Regulamenta a Lei $n^{\circ} 7.853$, de 24 de outubro de 1989, dispõe sobre a Política Nacional para a Integração da Pessoa Portadora de Deficiência, consolida as normas de proteção, e dá outras providências. Disponível em: http://www.planalto.gov.br/ccivil_03/ decreto/D3298.htm. Acesso em: 11 dez. 2019.

${ }^{43}$ LANNA JÚNIOR, Mário Cléber Martins (Org.). op. cit. 
administrativa do Ministério da Justiça para órgão colegiado de assessoramento vinculado à Secretaria Especial dos Direitos Humanos da Presidência da República (SEDH/PR). Posteriormente, o que era Conade passou a compor uma Subsecretaria Nacional de Promoção dos Direitos da Pessoa com Deficiência (2009), que em 2010 passou a ser a Secretaria Nacional de Promoção dos Direitos da Pessoa com Deficiência.

Mudanças ocorreram inclusive na nomenclatura: a expressão "pessoas portadoras de deficiência”, adotada na Constituição Federal de $1988(\mathrm{CF} / 88)^{44}$, bem como nas leis e políticas até a Convenção sobre os Direitos das Pessoas com Deficiência ${ }^{45}$, foi posteriormente alterada para "pessoa com deficiência" para designar esse grupo social. O movimento salienta que não almeja ser chamado de "especial", pois a luta política é pela cidadania, assim como não considera condizente ser "portador", que evoca uma condição de portar, quando se constitui uma condição que faz parte da pessoa.

Além desses avanços, foram inúmeras as novas organizações, associações e normatizações que se somaram às conquistas dos direitos das pessoas com deficiência no século XXI.

Como parte do marco legal de promoção dos direitos fundamentais da pessoa com deficiência, podemos citar as Leis n. 10.048/2000 e n. 10.098/2000, regulamentadas pelo Decreto n. $5.296 / 2004^{46}$, referentes a normas gerais e critérios básicos de acessibilidade e mobilidade e de atendimento prioritário a pessoas com deficiência; a Política Nacional de Saúde da Pessoa com Deficiência (Portaria MS/GM n. 1.060/2002) ${ }^{47}$, que estabelece diretrizes e responsabilidades do Sistema Único de Saúde (SUS) para reabilitação da pessoa com deficiência ${ }^{48}$; e a Convenção sobre os Direitos das Pessoas com Deficiência e o Protocolo Facultativo de 2006,

\footnotetext{
${ }^{44}$ BRASIL. Constituição da República Federativa do Brasil de 1988. Disponível em: http://www.planalto.gov. br/ccivil_03/constituicao/constituicaocompilado.htm. Acesso em: 11 dez. 2019.

${ }^{45}$ BRASIL. Decreto n. 6.949, de 25 de agosto de 2009. Promulga a Convenção Internacional sobre os Direitos das Pessoas com Deficiência e seu Protocolo Facultativo, assinados em Nova York, em 30 de março de 2007. Disponível em: http://www.planalto.gov.br/ccivil_03/_ato2007-2010/2009/decreto/d6949.htm. Acesso em: 11 dez. 2019.

${ }^{46}$ BRASIL. Decreto n. 5.296, de 2 de dezembro de 2004. Regulamenta as Leis ns. 10.048, de 8 de novembro de 2000, que dá prioridade de atendimento às pessoas que especifica, e 10.098, de 19 de dezembro de 2000, que estabelece normas gerais e critérios básicos para a promoção da acessibilidade das pessoas portadoras de deficiência ou com mobilidade reduzida, e dá outras providências. Disponível em: http://www.planalto.gov.br/ccivil_03/_ato2004-2006/2004/decreto/ d5296.htm. Acesso em: 11 dez. 2019.

${ }^{47}$ MINISTÉRIO DA SAÚDE. Gabinete do Ministro. Portaria n. 1.060, de 5 de junho de 2002. Disponível em: http://bvsms.saude.gov.br/bvs/saudelegis/gm/2002/prt1060_05_06_2002.html. Acesso em: 11 dez. 2019.

${ }^{48}$ BERNARDES, Liliane Cristina Gonçalves; ARAUJO, Tereza Cristina Cavalcanti Ferreira de. Deficiência, políticas públicas e bioética: percepção de gestores públicos e conselheiros de direitos. Cienc Saude Colet, v. 17, n. 9, p. 2435-2445, 2012. http://www.scielo.br/pdf/csc/v17n9/a24v17n9.pdf. http://dx.doi. org/10.1590/S1413-81232012000900024.
} 
dos quais o Brasil é signatário desde 2007, sem reservas, com ratificação pelo Congresso Nacional em $2008^{49}$.

Em janeiro de 2016, entrou em vigor a Lei Brasileira de Inclusão da Pessoa com Deficiência (Lei n. 13.146/2015) ${ }^{50}$, denominada também Estatuto da Pessoa com Deficiência, após tramitar no Congresso durante 12 anos. A lei, sancionada em julho de 2015, garante direitos nas áreas da educação, saúde, trabalho e infraestrutura, mas teve sete de seus artigos vetados.

É historicamente notória a luta contra a violação e pela garantia dos direitos básicos e pelo reconhecimento da dignidade e cidadania das pessoas com deficiência. Os movimentos buscam superar um modelo "médico" que considera a deficiência um problema pessoal, uma condição anormal que requer recuperação e adaptação da pessoa com deficiência por meio de uma mudança de conduta ${ }^{51}$. Eles defendem um modelo mais amplo, como proposto na Convenção das Nações Unidas sobre os Direitos das Pessoas com Deficiência em 2006: "a deficiência resulta da interação entre pessoas com deficiência e barreiras comportamentais e ambientais que impedem sua participação plena e eficaz na sociedade de forma igualitária". Portanto, a deficiência é uma interação, e não um atributo da pessoa. Nesse contexto, a principal causa da discriminação da pessoa com deficiência e do preconceito contra ela que precisa ser superada é de natureza cultural, e não biológica.

\section{Os testes genéticos como uma violência contra pessoas com deficiência}

Repetindo de certo modo o ideário eugenista, os testes genéticos que induzem à eliminação de embriões e fetos podem ser denunciados como mecanismos sofisticados que perpetuam a violência contra pessoas com deficiência, com maior impacto na infância dessas pessoas.

Há uma multiplicidade de leituras possíveis dentro do tema da violência, que, apesar de constituir um problema histórico, vem à tona na atualidade e se destaca nos ambientes sociais, levando pesquisadores a se direcionarem a seu estudo. Em um contexto de saúde pública, a violência contra a criança é um problema mundial, multicultural e epidemiologicamente permanente ${ }^{52}$, tomando dimensões ainda mais

\footnotetext{
${ }^{49}$ BRASIL. Decreto Legislativo n. 186, de 10 de julho de 2008. Aprova o texto da Convenção sobre os Direitos das Pessoas com Deficiência e de seu Protocolo Facultativo, assinados em Nova lorque, em 30 de março de 2007. Disponível em: http://www.planalto.gov.br/ccivil_03/CONGRESSO/DLG/DLG-186-2008.htm. Acesso em: 11 dez. 2019.

${ }^{50}$ BRASIL. Lei $n$. 13.146, 6 de julho de 2015. Institui a Lei Brasileira de Inclusão da Pessoa com Deficiência (Estatuto da Pessoa com Deficiência). Disponível em: http://www.planalto.gov.br/ccivil_03/_ato20152018/2015/lei/l13146.htm. Acesso em: 11 dez. 2019.

${ }^{51}$ BARTALOTTI, Celina Camargo. Inclusão social das pessoas com deficiência: utopia ou possibilidade? São Paulo: Paulus, 2006. p. 239-240.

${ }^{52}$ KRUG, Etienne G. et al. World report on violence and health. Geneva: World Health Organization; 2002. p. 66.
} 
amplas quando se trata de crianças com deficiência - em certos países, famílias com crianças com deficiência chegam a ser relegadas ao ostracismo. A violência contra a criança com deficiência ocorre três ou quatro vezes mais do que contra crianças em geral $^{53}$. Segundo Cavalcante e Minayo ${ }^{54}$, o risco é aumentado não pela deficiência em si, e sim está associado "aos fatores sociais, culturais e econômicos que criam um imaginário social negativo sobre a questão".

São diversas as formas de violência praticadas contra a criança: física, sexual, psicológica e simbólica, que é a destacada neste trabalho. A violência simbólica é a forma mais ampla de violência e se baseia na elaboração de crenças durante o processo de socialização e articulação de padrões sobre si mesma, sobre o outro e de visão de mundo, diferindo, portanto, da violência psicológica, que afeta o desenvolvimento de uma criança.

Segundo Bourdieu ${ }^{55}$, a violência simbólica é decorrente de um sistema simbólico em um âmbito social constituído por estruturas objetivas que independem das vontades individuais e que se impõem às práticas e às representações sobre essas práticas. É um tipo de violência que se expressa em uma forma arbitrária de imposição legítima e dissimulada. Para o autor, as representações evidenciam uma gênese social de esquemas de percepção, pensamento e ação que constituem o habitus. Os esquemas são produzidos no interior das estruturas sociais - os campos - de forma dinâmica, com "princípios geradores" de ação. Os campos são permeados por modos específicos de dominação e poder e, dessa forma, constituem campos de forças (assimétricas) e de lutas para conservá-los ou transformá-los. Nesse sentido, existe um poder de construção de realidade - o poder simbólico - que é uma forma invisível de poder, somente exercida com a cumplicidade daqueles que estão em sujeição, ou seja, com a cooperação e conivência dos que são subordinados e aceitam a lógica de integração e consenso.

Nessa relação de poder simbólico, interesses particulares podem ser apresentados como interesses comuns, manifestando-se a violência na própria estrutura em que ele se produz e se reproduz. A leitura dessa realidade faz entender que ela não requer o emprego de violência física ou de qualquer outro artifício que consuma energia, mas sim da existência de sentido e conhecimento que modificam as relações de força, levando o indivíduo a se submeter à violência exercida sem questionar sua

\footnotetext{
${ }^{53}$ FUNDO DAS NAÇÕES UNIDAS PARA A INFÂNCIA - UNICEF. Situação mundial da infância: 2013. Crianças com deficiência. Brasília-DF: UNICEF; 2013. Disponivel em: http://www.unicef.org/brazil/pt/PT_SOWC2013. pdf. Acesso em: 11 nov. 2015.

${ }^{54}$ CAVALCANTE, Fátima Gonçalves; MINAYO, Maria Cecília de Souza. Representações sociais sobre direitos e violência na área da deficiência. Ciênc. saúde coletiva, Rio de Janeiro, v. 14, n. 1, p. 57-66, fev. 2009. Disponível em <http://www.scielo.br/scielo.php?script=sci_arttext\&pid=S1413-81232009000100011\&ln g=pt\&nrm=iso>. http://dx.doi.org/10.1590/S1413-81232009000100011.

${ }^{55}$ BOURDIEU, Pierre. O poder simbólico. Trad. Fernando Tomaz. Rio de Janeiro: Bertrand Brasil, 1989. p. 8.
} 
legitimidade ${ }^{56}$. Os discursos que diferenciam a eugenia estatal da eugenia familiar, defendendo-a com o pressuposto de direito do casal ao exercício da liberdade, podem ser compreendidos como uma forma de significação que altera as relações de força. Nesses casos, a eugenia é promovida como um poder simbólico através do discurso humanista de defesa da liberdade do casal de optar pela eugenia.

A violência simbólica é, ainda, uma forma de constrangimento dentro de uma realidade vivenciada que pode ser até imperceptível, mas que se adequa a determinadas condições sociais e que vai aos poucos produzindo a redução da identidade e da individualidade daquele que está na condição de submissão.

Uma das representações da violência simbólica contra as pessoas com deficiência é a forma como foram chamadas até meados do século XX: "aleijados",

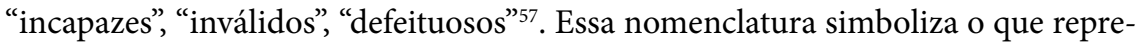
sentavam socialmente. Posteriormente, os próprios movimentos reivindicaram, em um campo de força assimétrica, que fossem chamadas pelo substantivo "pessoa", deixando eminente a não condição de "coisa", como forma simbólica de superar a inferioridade e desvalorização trazida pelos termos passados.

Embora essa violência esteja vinculada ao ambiente simbólico, existem manifestações visíveis de poder e violência, que se expressam quando as pessoas são "[...] espancadas, violentadas, exploradas (...) dentro de uma experiência subjetiva das relações de dominação" ${ }^{\text {"E }}$. É nesse contexto que a exploração de crianças deficientes e a violência contra elas são muito maiores se comparadas às crianças que não têm deficiência. Além disso, a representação simbólica torna legítima - e dissimulada - a violência da eugenia praticada por meio do aborto e da não transferência de embriões por identificar tais casos "deficientes".

O sistema de dominação, marcado pela violência simbólica, acaba por se institucionalizar e se reproduzir em virtude da desigualdade e da exclusão dos dominados, e se insere nos mais variados grupos e instituições, como família, igreja, escola e Estado. Um exemplo de reprodução dessa violência foi a preparação para o AIPD (1981), em que o Brasil instalou uma comissão nacional formada por representantes do Poder Executivo e várias outras entidades, sem incluir representantes de entidades formadas por pessoas com deficiência ${ }^{59}$. Foi necessária a redação de uma carta ao presidente da República para que as pessoas com deficiência conquistassem uma vaga na comissão que as representaria.

\footnotetext{
${ }^{56}$ BOURDIEU, Pierre. A dominação masculina. Tradução Maria Helena. Kühner. 3. ed. Rio de Janeiro: Bertrand Brasil, 2003.

${ }^{57}$ BERNARDES, Liliane Cristina Gonçalves; ARAUJO, Tereza Cristina Cavalcanti Ferreira de. Deficiência, políticas públicas e bioética: percepção de gestores públicos e conselheiros de direitos, cit., p. 2435-2445.

${ }^{58}$ BOURDIEU, Pierre. A dominação masculina, cit., p. 46.

${ }^{59}$ LANNA JÚNIOR, Mário Cléber Martins (Org.). op. cit., p. 42.
} 
As estruturas sociais têm valores patriarcais e sociais capazes de influenciar na formação dos indivíduos, interferindo em seu espaço e tempo, com vistas a dar continuidade às relações entre os grupos e classes na vivência de dominantes e dominados. Superar a influência dessas estruturas passa pela identificação e pelo reconhecimento das formas de violência pelas quais elas atuam. Essas estruturas renovam-se e se atualizam nos discursos de dominação. As pessoas com deficiência têm sido protagonistas na superação da visão preconceituosa e excludente por meio da participação social. Contudo, como destaca Lana Junior,

[...] esse grupo de pessoas pouco interesse despertou nos historiadores e se encontra à margem dos estudos históricos e sociológicos sobre os movimentos sociais no Brasil, apesar de serem atores que empreenderam, desde o final da década de 1970, e ainda empreendem intensa luta por cidadania e respeito aos Direitos Humanos ${ }^{60}$.

Os movimentos das pessoas com deficiência empreendem esforços, principalmente, para o reconhecimento de que elas não são o problema, e sim a estrutura de reconhecimento social que problematiza e exerce violência, causando-lhes prejuízos no desempenho de seus papéis sociais.

\section{Considerações finais}

Este artigo apresentou que a temática estudada revela um conflito ético: pode a sociedade acatar normas que regulamentam descartes de embriões e fetos por serem portadores de determinadas características genéticas, sendo que ela mesma regulamenta e incentiva a inclusão social de pessoas com essas características? Entendemos que a prática de eliminação de embriões e fetos pode ser compreendida como violência contra a pessoa com deficiência - o tipo de violência que está enraizado e justificado por teorias e, por isso, uma violência simbólica, que se repete, perpetuando a exclusão, muitas vezes despercebida por aqueles que a praticam. É no contexto da necessidade primária do reconhecimento desse tipo de violência que a presente discussão propõe a superação das construções sociais simbólicas excludentes.

A exclusão de seres humanos por meio de testes genéticos alimenta-se de um dos pressupostos da eugenia clássica: o reducionismo genético. O reducionismo genético apresenta uma visão fechada, na qual a vida humana é reduzida a um único tipo de causa física: a herança genética ${ }^{61}$. Lewontin afirma que o reducionismo biológico fundamenta-se em três ideias propostas conjuntamente: (i) nós somos diferentes uns dos outros por causa de diferenças inatas; (ii) essas diferenças inatas

\footnotetext{
${ }^{60}$ LANNA JÚNIOR, Mário Cléber Martins (Org.). op. cit., p. 12.

${ }^{61}$ TAUER, Carol A. The human significance of the genome project (1992). In: Shannon, T. A. (Ed.). Genetic engineering: a documentary history. Westport: Greenwood Press, 1999. p.107.
} 
são herdadas biologicamente; (iii) a natureza garante a formação de uma sociedade hierárquica. Assim, "estas três ideias juntas formam o que chamamos de ideologia do determinismo biológico" ${ }^{62}$, pois o reducionismo leva ao determinismo, que, por sua vez, passa a constituir uma ideologia, porque pretende explicar toda a complexidade da vida e da realidade social a partir dos constituintes biológicos. As dimensões psicológicas, sociais, jurídicas, religiosas e artísticas passam a ser compreendidas como variantes determinadas pelo fator biológico.

Os movimentos em prol das pessoas com deficiência já alcançaram muitos avanços legislativos e políticos nas últimas décadas, contudo ainda têm muito a avançar em relação ao modelo médico ou determinista, que foi construído e reforçado socialmente apontando a deficiência como um problema a ser eliminado. $\mathrm{O}$ ápice desse discurso se dá pela legitimidade conferida aos testes genéticos como forma de superação do problema das deficiências pela eliminação do próprio "deficiente". Até mesmo na bioética, numa perspectiva utilitarista, a violência contra as pessoas com deficiência se dá quando a qualidade de vida é tomada como parâmetro de atribuição de valor a vida. Bernardes et al. ${ }^{63}$ questionam se "uma existência com deficiência é necessariamente miserável, em razão da própria deficiência, ou se as limitações enfrentadas são um reflexo de uma sociedade pouco inclusiva”.

Dessa forma, compreendemos que a inclusão, a promoção dos direitos e o reconhecimento da dignidade da pessoa com deficiência passam por uma estrutura ampla e complexa de representação social. Nessa estrutura, o discurso ideológico eugênico, que utiliza ferramentas genéticas para cumprir seus objetivos e fundamentar seus pressupostos, constitui um elemento de conflito e retrocesso. Isso porque vai contra a promoção da valorização da diversidade humana, cria critérios de qualificação de "superiores" e "indesejáveis", desrespeita o direito de todos à reprodução e ainda é arrogante e injusta, principalmente com aqueles que lutam pela inclusão e defendem a dignidade das pessoas com deficiência.

\section{Referências}

BARTALOTTI, Celina Camargo. Inclusão social das pessoas com deficiência: utopia ou possibilidade? São Paulo: Paulus, 2006.

${ }^{62}$ LEWONTIN, Richard. Biology as ideology: the doctrine of DNA. New York: HarperPerenial, 1992. p. 23.

${ }^{63}$ BERNARDES, Liliane Cristina Gonçalves; MAIOR, Izabel Maria Madeira de Loureiro; SPEZIA, Carlos Humberto; ARAUJO, Tereza Cristina Cavalcanti Ferreira de. Pessoas com deficiência e políticas públicas no Brasil: reflexões bioéticas. Cienc Saude Colet, vol.14, n.1, p. 31-38, 2009. Disponível em: http://www. scielo.br/pdf/csc/v14n1/a08v14n1.pdf. http://dx.doi.org/10.1590/S1413-81232009000100008. 
BATTISTELLA, Linamara Rizzo. Celebrando os 30 anos do AIPD: uma história de lutas e conquistas de direitos. In: 30 ANOS do AIPD: Ano Internacional das Pessoas Deficientes 1981-2011. São Paulo: Imprensa Oficial do Estado de São Paulo, 2011. Disponível em: http://uniapae.apaebrasil.org.br/wp-content/uploads/2019/10/30-ANOS-DO-AIPD-ANOINTERNACIONAL-DAS-PESSOAS-DEFICIENTES-1981-2011.pdf.

BEIGUELMAN, Bernard. Genética e ética. In: PESSINI, Leo, BARCHIFONTAINE, Christian de Paul (Orgs.). Fundamentos da bioética. São Paulo: Paulus; 1996. p. 108-123.

BERNAL, Ricardo Miguel Luque; BEJARANO, Roberto José Buitrago. Is genetic counseling a form of eugenics? Rev. Cienc. Salud, Bogotá-CO, v.16, n. 1, p. 10-26, ene./abr. 2018.

BERNARDES, Liliane Cristina Gonçalves; ARAUJO, Tereza Cristina Cavalcanti Ferreira de. Deficiência, políticas públicas e bioética: percepção de gestores públicos e conselheiros de direitos. Cienc Saude Colet, v. 17, n. 9, p. 2435-2445, 2012. http://www.scielo.br/pdf/csc/ v17n9/a24v17n9.pdf. http://dx.doi.org/10.1590/S1413-81232012000900024.

BERNARDES, Liliane Cristina Gonçalves; MAIOR, Izabel Maria Madeira de Loureiro; SPEZIA, Carlos Humberto; ARAUJO, Tereza Cristina Cavalcanti Ferreira de. Pessoas com deficiência e políticas públicas no Brasil: reflexões bioéticas. Cienc Saude Colet, vol.14, n.1, p. 31-38, 2009. Disponível em: http://www.scielo.br/pdf/csc/v14n1/a08v14n1.pdf. http://dx.doi. org/10.1590/S1413-81232009000100008.

BORGHESI, Alessandro et al. Intersociety policy statement on the use of whole-exome sequencing in the critically ill newborn infant. Italian Journal of Pediatrics, v. 43, n. 100, 2017. Disponível em: https://ijponline.biomedcentral.com/articles/10.1186/s13052-017-0418-0.

BOURDIEU, Pierre. A dominação masculina. Tradução Maria Helena. Kühner. 3. ed. Rio de Janeiro: Bertrand Brasil, 2003.

BOURDIEU, Pierre. O poder simbólico. Trad. Fernando Tomaz. Rio de Janeiro: Bertrand Brasil, 1989.

BUCHANAN, Allen, BROCK, Dan W., DANIELS, Norman. From chance to choice: genetics and justice. New York: University Press Cambridge, 2000.

CAVAlCANTE, Fátima Gonçalves; MINAYO, Maria Cecília de Souza. Representações sociais sobre direitos e violência na área da deficiência. Ciênc. saúde coletiva, Rio de Janeiro, v. 14, n. 1, p. 57-66, fev. 2009. Disponível em <http://www.scielo.br/scielo.php?script=sci_ arttext\&pid=S1413-81232009000100011\&lng=pt\&nrm=iso $>$. http://dx.doi.org/10.1590/ S1413-81232009000100011.

CONDIT, Celeste Michele. The meanings of the gene: public debates about human heredity. Madison: University of Wisconsin Press; 1999.

DYCK, Arthur J. Eugenics in historical and ethical perspective. In: KILNER, John F.; PENTZ, Rebecca D.; YOUNG, Frank (Eds.). Genetic ethics: do the ends justify the genes? Grand Rapids: Eerdmans Publishing Company, 1997. p. 25-39. 
FUNDO DAS NAÇÕES UNIDAS PARA A INFÂNCIA - UNICEF. Situação mundial da infância: 2013. Crianças com deficiência. Brasília-DF: UNICEF; 2013. Disponível em: http:// www.unicef.org/brazil/pt/PT_SOWC2013.pdf. Acesso em: 11 nov. 2015.

GRAVES, C.E.; HARRISON, M.R.; PADILLA B.E. Minimally invasive fetal surgery. Clin Perinatol, v. 44, n. 4, p. 729-751, 2017. http://dx.doi.org/10.1016/j.clp.2017.08.001.

HANDYSIDE, A.H et al. Pregnancies from biopsied human preimplantation embryos sexed by Y-specific DNA amplification. Nature, v. 19, n. 344, p. 768-770, Apr. 1990. http://dx.doi. org/10.1038/344768a0.

KELVES, Daniel J. In the name of eugenics: genetics and the uses of human heredity. New York: Alfred A. Knopf, 1985.

KITCHER, Philip. Utopian eugenics and social inequality. In: SLOAN, Phillip R. (Ed.). Controlling our destinies: historical, ethical, and theological perspectives on the Human Genome Project. Notre Dame: University of Notre Dame Press, 2000. p. 229-262.

KRUG, Etienne G. et al. World report on violence and health. Geneva: World Health Organization; 2002.

KULIEV, A; VERLINSKY, Y. Preimplantation diagnosis: a realistic option for assisted reproduction and genetic practice. Current Opinion in Obstetrics and Gynecology, v. 17, n. 2, p. 179-183, May 2005. http://dx.doi.org/10.1097/01.gco.0000162189.76349.c5.

LANNA JÚNIOR, Mário Cléber Martins (Org.). História do movimento político das pessoas com deficiência no Brasil. Brasília-DF: Secretaria de Direitos Humanos, Secretaria Nacional de Promoção dos Direitos da Pessoa com Deficiência, 2010. Disponível em: http://www.mpsp.mp.br/portal/page/portal/documentacao_e_divulgacao/doc_biblioteca/ bibli_servicos_produtos/BibliotecaDigital/BibDigitalLivros/TodosOsLivros/historia_ movimento_pcd_brasil.pdf.

LEITE, Tatiana Henriques; HENRIQUES, Rodrigo Arruda de Holanda. Bioética em reprodução humana assistida: influência dos fatores sócio-econômico culturais sobre a formulação das legislações e guias de referência no Brasil e em outras nações. Physis, Rio de Janeiro, v. 24, n. 1, p. 31-47, mar. 2014. Disponível em: http://www.scielo.br/scielo. php? script=sci_arttext\&pid=S0103-73312014000100031\&lng=en\&nrm=iso. http://dx.doi. org/10.1590/S0103-73312014000100003.

LEWONTIN, Richard. Biology as ideology: the doctrine of DNA. New York: HarperPerenial, 1992.

LO, Y. M. et al. Presence of fetal DNA in maternal plasma and serum. Lancet, v. 16, n. 350, p. 485-487, Aug. 1997. http://dx.doi.org/10.1016/S0140-6736(97)02174-0.

LUNA, Florencia; RIVERA LÓPEZ, Eduardo. Ética y genética: los problemas morales de la genética humana. Buenos Aires: Catálogos, 2004. 
MARAMBIO, José Tomás Alvarado; ALCÁNTARA, Manuel J. Santos. Ethical problems with the preimplantation genetic diagnosis of human embryos. Acta Bioethica, v. 24, n. 1, p. 75-83, 2018. Disponível em: https://scielo.conicyt.cl/pdf/abioeth/v24n1/1726-569X-abioeth-24-01-00075.pdf.

MARKS, Jonathan. Human biodiversity: genes, race and history. New York: Aldine de Gruyter, 1995.

OMIM Gene Map Statistics. Disponível em: http://www.omim.org/statistics/geneMap. Acesso em: 07 nov. 2018.

POLÍTICA Nacional de Educação Especial na Perspectiva da Educação Inclusiva. BrasíliaDF: MEC/SEESP, 2008. Documento elaborado pelo Grupo de Trabalho nomeado pela Portaria no 555/2007, prorrogada pela Portaria no $948 / 2007$, entregue ao Ministro da Educação em 07 de janeiro de 2008. Disponível em: http://portal.mec.gov.br/arquivos/ pdf/politicaeducespecial.pdf.

ROTTERDAM ESHRE/ASRM-Sponsored PCOS Consensus Workshop Group. Revised 2003 consensus on diagnostic criteria and long-term health risks related to polycystic ovary syndrome. Fertil Steril, v. 81, n. 1, p.19-25, Jan. 2004. http://dx.doi.org/10.1016/j. fertnstert.2003.10.004.

SANCHES, Mário Antônio. Brincando de Deus: bioética e as marcas sociais da genética. São Paulo: Ave Maria, 2007.

SCHMIDT, L. C. et al. Noninvasive fetal RHD genotyping from maternal plasma in an admixed Brazilian population. Genet Mol Res, 0v. 13, n. 1, p. 799-805, Feb. 2014.

SLOAN, Philip R. Controlling our destinies: historical, ethical, and theological perspectives on the Human Genome Project. Notre Dame: University of Notre Dame Press, 2000.

TABOR, A; ALFIREVIC, Z. Update on procedure-related risks for prenatal diagnosis techniques. Fetal Diagn Ther, v. 27, n. 1, p. 1-7, Dec. 2009. http://dx.doi.org/10.1159/000271995.

TAUER, Carol A. The human significance of the genome project (1992). In: Shannon, T. A. (Ed.). Genetic engineering: a documentary history. Westport: Greenwood Press, 1999. p. 103-110.

VIERNES, H. Enabling reproductive genomics and inherited disease research with the Ion S5 next-generation sequencing system. Thermo Fisher Scientific [Technical Report], 2015 Disponível em: https://tools.thermofisher.com/content/sfs/brochures/Ion-S5-S5XL-AppNote-Inherited-Disease.pdf.

WATSON, J. D; BERRY, A. DNA: o segredo da vida. Trad. Carlos Afonso Malferrari. São Paulo: Companhia das Letras, 2005.

WOLFF, P; MARTINHAGO, C.D; UENO, J. Diagnóstico genético pré-implantacional: uma ferramenta importante para a rotina de fertilização in vitro? Femina, v. 37, n. 6, p. 297-303, jun. 2009. 
Sanches M. A., Simão-Silva D. P., Oliveira H. I.

Mário Antônio Sanches - Pós-Doutorado em Bioética pela Universidad Pontificia Comillas (Madri, Espanha); doutorado em Teologia pela Universidad Pontificia Comillas (Madri, Espanha). Professor titular da Pontifícia Universidade Católica do Paraná (PUC-PR). Curitiba/ PR, Brasil.E-mail: m.sanches@pucpr.br

Daiane Priscila Simão-Silva - Pós-Doutorado em Bioética pela Pontifícia Universidade Católica do Paraná (PUC-PR); doutorado em Genética pela Universidade Federal do Paraná (UFPR). Professora no Programa de Pós-Graduação em Bioética da PUC-PR. Curitiba/PR, Brasil.

Houda Izabela De Oliveira - Mestrado em Bioética pela Pontifícia Universidade Católica do Paraná (PUC-PR). Enfermeira do Hospital Pequeno Príncipe, Curitiba/PR, Brasil. 